\title{
Surgical Outcome of Two Difficult Cases with Predominant Proximal Pulmonary Artery Lesions of Chronic Thromboembolic Pulmonary Hypertension
}

\author{
Takashi Murashita, MD, Hitoshi Ogino, MD, PhD, Hitoshi Matsuda, MD, PhD, Hiroaki Sasaki, MD, PhD, \\ Hiroshi Tanaka, MD, PhD, Yutaka Iba, MD, Keitaro Doumae, MD, Tatsuki Fujiwara, MD, \\ Masatoshi Shimada, MD, and Naoki Okuda, MD
}

Pulmonary endarterectomy (PEA) for chronic thromboembolic pulmonary hypertension (CTEPH) is still challenging. The outcome of patients with proximal pulmonary artery disease is generally better than that of a distal lesion. However, we experienced poor results in two difficult cases having predominant proximal lesions even after effective PEA. Both of them had a long-time history of CTEPH and preoperative condition was critical. Although relatively large amount of thickened intima with massive thrombi were extracted from the proximal pulmonary arteries, they required postoperative percutaneous cardiopulmonary support due to residual pulmonary hypertension. Both of them finally died from pulmonary bleeding and adult respiratory distress syndrome.

Key words: chronic thromboembolic pulmonary hypertension, pulmonary endarterectomy, proximal lesion, distal lesion

\section{INTRODUCTION}

$S_{\mathrm{d}}^{\mathrm{in}}$ ince the San Diego group established surgical procedures for chronic thromboembolic pulmonary hypertension $(\mathrm{CTEPH}){ }^{1-3)}$ successful results of pulmonary endarterectomy (PEA) have been reported from other institutions. However, PEA is still challenging and technically demanding with higher mortality than usual cardiac surgeries. In particular, for patients with distal pulmonary artery disease, PEA is, technically, more difficult and, obviously, its outcome is much poorer than that of proximal disease. ${ }^{4-7)}$ In our previous study, we also reported that the mortality of proximal and distal disease after

Department of Cardiovascular Surgery, National Cerebral and Cardiovascular Surgery, Suita, Osaka, Japan

Received: January 4, 2011; Accepted: March 15, 2011

Corresponding author: Hitoshi Ogino, MD. Department of Cardiovascular Surgery, National Cerebral and Cardiovascular Surgery, 5-7-1 Fujishirodai, Suita, Osaka 565-8565 Japan

Tel: +81-6-6833-5012, Fax: +81-6-6833-9865

E-mail: hogino@hsp.ncvc.go.jp
PEA was $3.9 \%$ and $13.5 \%$, respectively. ${ }^{7}$ In this report, we present two exceptionally difficult cases of severe CTEPH with proximal lesions who died from residual pulmonary hypertension after effective likelihood PEA.

\section{Case 1}

A 40-year-old female with 10 years history of CTEPH who had a deficiency of protein $\mathrm{S}$ and $\mathrm{C}$ was referred to our hospital for PEA. Since the onset of acute pulmonary embolism ten years ago, dyspnea on effort had gradually progressed. She started home oxygen therapy (HOT) 6 years ago. On admission, she could not walk at all and was always bed-ridden. Her New York Heart Association (NYHA) class was IV. She was on dobutamine of $2 \mu \mathrm{g} /$ $\mathrm{kg} / \mathrm{min}$ and intravenous prostacyclin therapy with epoprostenol sodium of $4.5 \mathrm{ng} / \mathrm{kg} / \mathrm{min}$. Her oxygen saturation on pulse oximetry was $82 \%$ even under HOT. The cardiac catheter study showed that the mean pulmonary artery pressure (mPAP) was $59 \mathrm{mmHg}$ and pulmonary vascular resistance (PVR) was 1855 dynes $\cdot \mathrm{sec}^{-1} \cdot \mathrm{cm}^{-5}$. The cardiac output and cardiac index were $2.4 \mathrm{~L} / \mathrm{min}$ and 1.7 


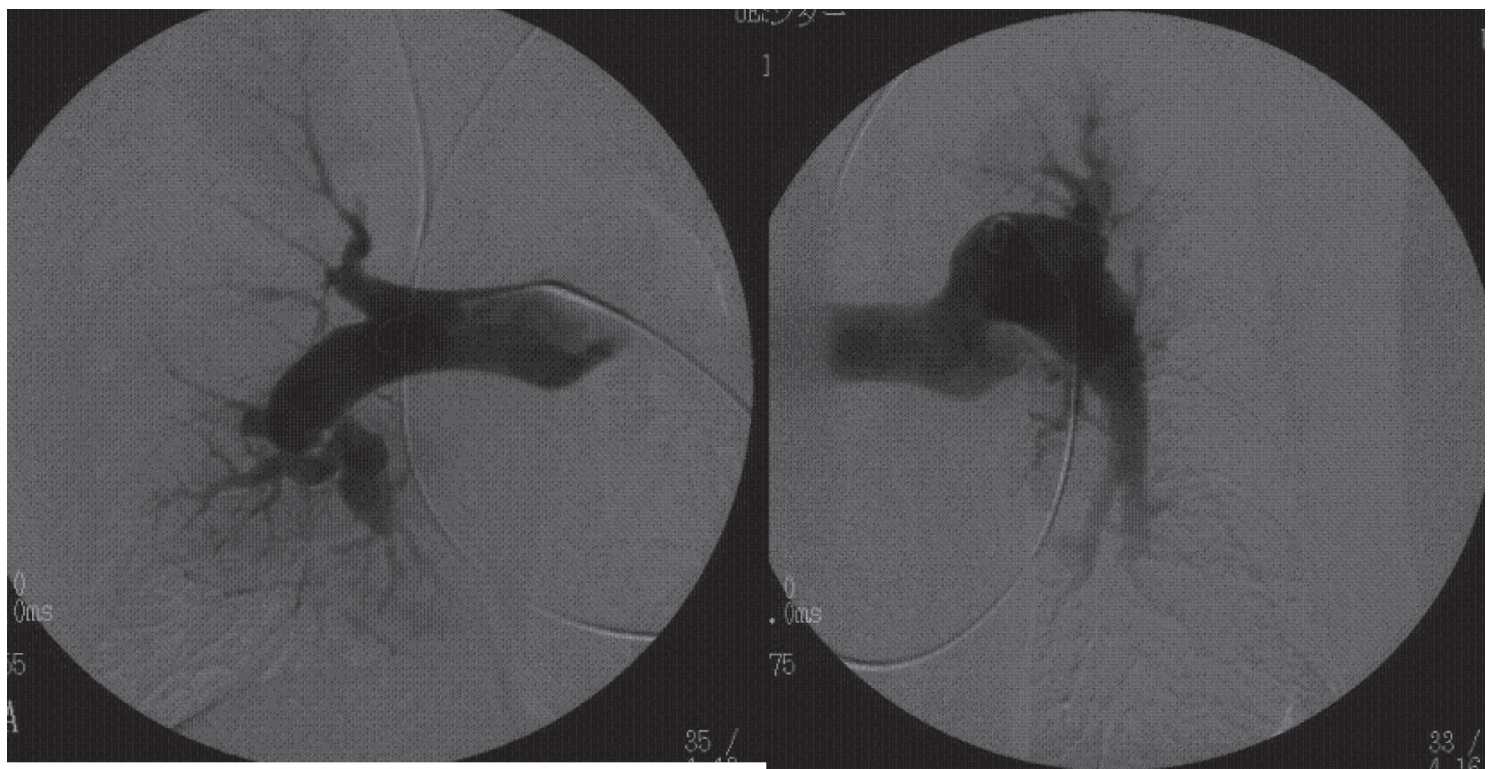

Fig. 1 Preoperative pulmonary artery angiography in case 1. Massive thrombi in the main region and diffuse thrombi in the distal region of both pulmonary arteries.

A: Right pulmonary artery, B: Left pulmonary artery

$\mathrm{L} / \mathrm{min} / \mathrm{m}^{2}$. Pulmonary artery angiography (PAG) shows large thrombi in the both main pulmonary arteries and segmental artery lesions to be accessible at PEA (Fig. 1). Transthoracic echocardiography showed severe tricuspid regurgitation and patent foramen ovale (PFO). Brain natriuretic peptide (BNP) level was $1111 \mathrm{ng} / \mathrm{ml}$.

We performed PEA using intermittent deep hypothermia circulatory arrest (DHCA) at $18^{\circ} \mathrm{C} .^{1-3)}$ Initially, atheromatous change of old thrombi in the both main pulmonary arteries was found. A large amount of thickened intima with them was extracted from the both proximal pulmonary arteries, although PEA was not smoothly done for the distal lesions (Fig. 3A). The total circulatory arrest time was 50 minutes. Tricuspid annuloplasty using a $30 \mathrm{~mm}$ Edwards $\mathrm{MC}^{3}$ ring and direct closure of PFO were concomitantly performed. Despite PEA, residual pulmonary hypertension developed with mPAP of $60 \mathrm{mmHg}$. Weaning from cardiopulmonary bypass (CPB) was unsuccessful and percutaneous cardiopulmonary support (PCPS) was used via a femoro-femoral veno-arterial circuit. The patient was transferred to the intensive care unit. The postoperative systemic blood pressure was 100/60 mmHg, PVR was 1538 dynes $\cdot \mathrm{sec}^{-1}$. $\mathrm{cm}^{-5}$, and cardiac output was $2.0 \mathrm{~L} / \mathrm{min}$. Weaning from PCPS was attempted several times on the following days, but it failed due to residual pulmonary hypertension and right heart failure. On postoperative day (POD) 6, massive pulmonary bleeding from the bronchial artery sud- denly occurred with support of PCPS and use of heparin. Emergency coil embolization of one branch of the right internal thoracic artery was carried out, and hemostasis was achieved. After that, the condition got stabilized and she was weaned from PCPS on POD 12. However, spontaneous pneumothorax caused deterioration of the respiratory condition with pulmonary hypertension, and PCPS was required on POD 14. In addition, massive pulmonary bleeding occurred again on POD 19, and emergency coil embolization of collateral arteries via the right subclavian artery was performed. Her condition gradually worsened due to pneumonia and acute respiratory distress syndrome (ARDS). Finally, she died from respiratory failure and multiple organ failure on POD 45. The autopsy showed severe pneumonia and bleeding, which made it difficult to identify distal pulmonary lesions.

\section{CASE 2}

A 65-year-old male with an 11-year history of CTEPH was referred to our hospital for PEA. Eleven years ago, he also suffered from acute pulmonary embolism and was treated medically. HOT was started at that time. Since then, dyspnea on effort has gradually progressed. On admission, his NYHA class was IV. He was also on dubutamine, $2 \mu \mathrm{g} / \mathrm{kg} / \mathrm{min}$. Deep venous thrombosis (DVT) was detected by ultrasound examination. The cardiac catheter study showed that preoperative mPAP was 


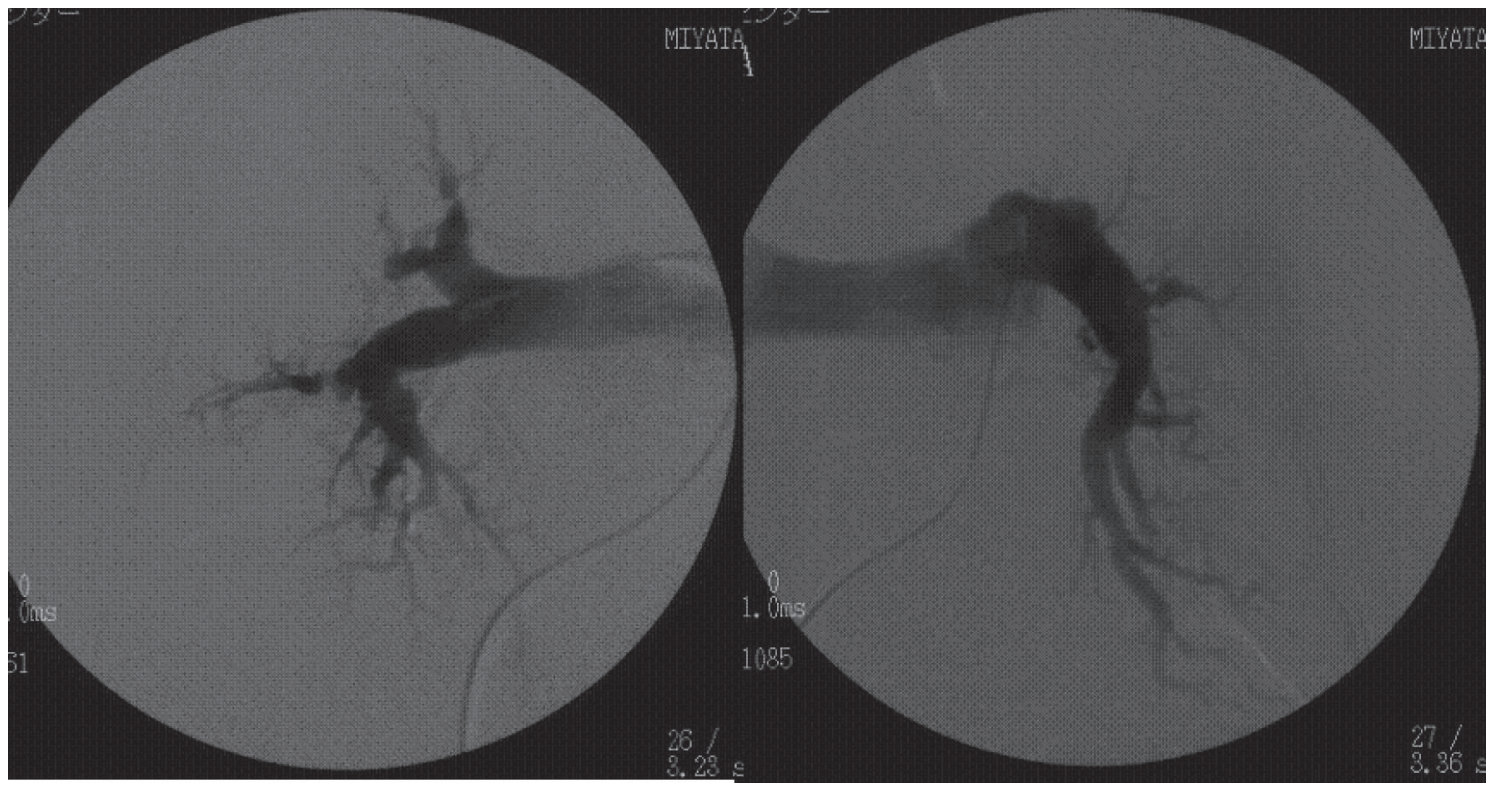

Fig. 2 Preoperative pulmonary artery angiography in case 2. Large thrombi in the right main pulmonary artery and diffuse thrombi in the left pulmonary artery.

A: Right pulmonary artery, B: Left pulmonary artery
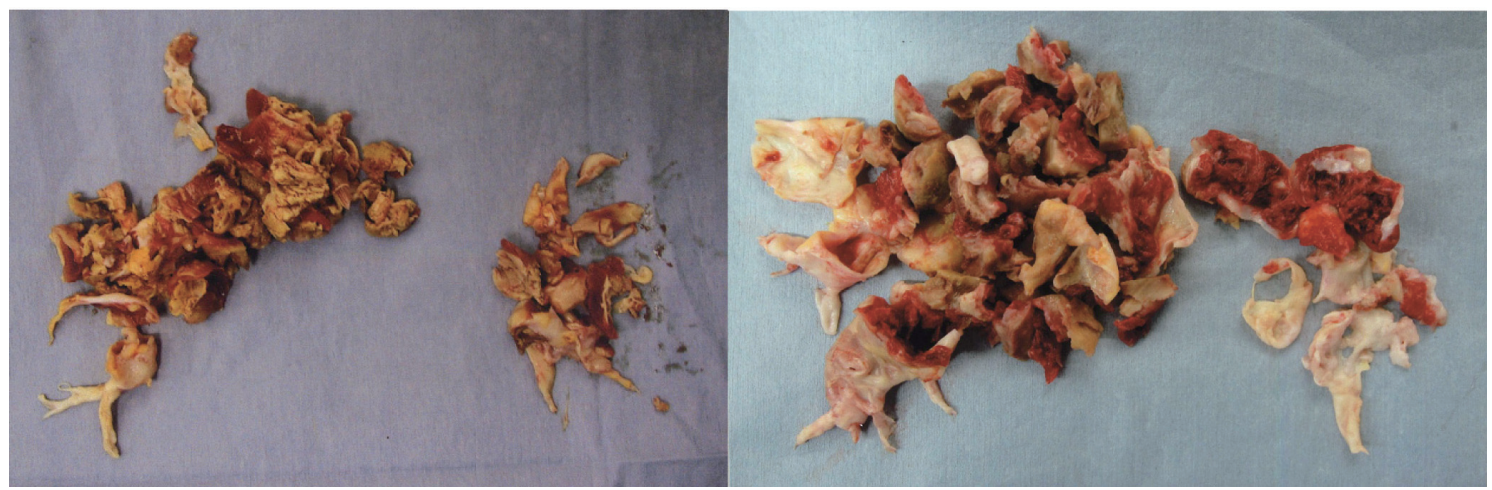

A

Fig. 3 Thickened endothelium with old thrombi extracted from pulmonary arteries in case 1 (A), case 2 (B).

$76 \mathrm{mmHg}$, and PVR was $2,593 \mathrm{dynes} \cdot \mathrm{sec}^{-1} \cdot \mathrm{cm}^{-5}$. The cardiac output and cardiac index were $2.2 \mathrm{~L} / \mathrm{min}$ and $1.4 \mathrm{~L} /$ $\mathrm{min} / \mathrm{m}^{2}$. The PAG showed a large thrombi in the right main pulmonary artery and diffuse thrombi in the left pulmonary artery (Fig. 2). Transthoracic echocardiography revealed mild to moderate tricuspid regurgitation. Coronary angiography revealed $75 \%$ stenosis of the left anterior descending artery (LAD). The BNP level was $1840 \mathrm{ng} / \mathrm{ml}$.

PEA using intermittent DHCA at $18^{\circ} \mathrm{C}$ with concomitant coronary artery bypass grafting to LAD using saphenous vein graft was carried out. A large amount of thickened intima with old thrombi was extracted from the both sides of pulmonary arteries, predominantly from the proximal pulmonary arteries (Fig. 3B). The total circulatory arrest time was 31 minutes. Weaning from CPB was successful, and he was transferred to the intensive care unit without an assisted device. The postoperative systemic blood pressure was $120 / 80 \mathrm{mmHg}$, mPAP was $45 \mathrm{mmHg}$, PVR was 1347 dynes $\cdot \mathrm{sec}^{-1} \cdot \mathrm{cm}^{-5}$, and cardiac output was $1.9 \mathrm{~L} / \mathrm{min}$.

On POD 2, he was extubated. However, severe reperfusion lung damage occurred on POD 3, and re-intubation was required. On POD 6, PCPS via a femoro-femoral veno-arterial circuit was needed due to deterioration of the hemodynamic state with pulmonary hypertension and severe hypoxia. Chest XP showed findings of ARDS. Steroid pulse therapy was carried out, and his general condition was temporarily improved. He was weaned from PCPS once on POD 9; however, pulmonary bleeding 
and pneumonia occurred. ARDS had gradually worsened. Finally, he died from ARDS, pulmonary bleeding, and pneumonia on POD 29. The autopsy showed both sides of pulmonary bleeding and severe pyrothorax.

\section{DisCUSSION}

We have reported a relatively low mortality and favorable prognosis with long-term survival after PEA.' The outcome is better in patients with proximal pulmonary artery lesions, although that of patients with distal disease is, in contrast, poorer. ${ }^{4-6)}$ In addition, a previous study showed that patients with a PVR greater than 1,100 dynes $\cdot \mathrm{sec}^{-1} \cdot \mathrm{cm}^{-5}$ and an mPAP greater than $50 \mathrm{mmHg}$ had a poor outcome. ${ }^{8)}$ Jamieson et al also reported that 17 of 22 hospital deaths $(77 \%)$ were related to residual pulmonary hypertension, and the mortality rate was $31 \%$ when the postoperative PVR was $>500$ dynes $\cdot \mathrm{sec}^{-1} \cdot \mathrm{cm}^{-5}$, and $0.9 \%$ when it was $<500$ dynes $\cdot \mathrm{sec}^{-1} \cdot \mathrm{cm}^{-5}$. ${ }^{6}$ In our cases, both had high mPAP and PVR preoperatively, and it did not improve significantly, even after PEA. The postoperative mPAP was $60 \mathrm{mmHg}$ in case 1 and 45 $\mathrm{mmHg}$ in case 2, and the postoperative PVR was 1538 dynes $\cdot \mathrm{sec}^{-1} \cdot \mathrm{cm}^{-5}$ in case 1 and 1347 dynes $\cdot \mathrm{sec}^{-1} \cdot \mathrm{cm}^{-5}$ in case 2. Management of residual pulmonary hypertension is still difficult and depends on the severity of pulmonary hypertension, because PVR is commonly fixed and usually does not respond to vasodilators. ${ }^{9)}$ Sato et al reported two cases of CTEPH in which they successfully prevented postoperative pulmonary hypertension and hypoxia caused by severe reperfusion pulmonary edema by the use of a percutaneous cardiopulmonary support (PCPS). ${ }^{10)}$ In our series, 15 patients (11.5\%) of 130 patients between 1995 and 2009 including the two presented cases required PCPS for residual pulmonary hypertension with/without pulmonary bleeding. Recently, 8 patents (53.3\%) were weaned from it, and $5(33.3 \%)$ of them survived successfully, although the two patients who presented eventually died.

In our cases, both of the patients had a long history of CTEPH more than 10 years and were critically ill with NYHA class IV. Preoperative PVR and mPAP were significantly high. PEA seemed to have a likelihood of success with removal of a large amount of thickened intima; however pulmonary hypertension remains postoperatively. It was speculated that the cause was coexisting distal lesions that had developed in the long-term severe pulmonary hypertension due to a remodeling mechanism. In addition, pulmonary bleeding, unfortunately, occurred from the lesions of the pulmonary infarction having large collateral arteries in such severe cases having a long history of CTEPH.

In conclusion, some caution is still required in PEA for cases even with proximal type CTEPH having a long history and severe pulmonary hypertension with NYHA class IV.

\section{REFERENCES}

1) Daily PO, Dembitsky WP, Iversen S, Moser KM, Auger W. Surgical management of chronic pulmonary embolism: surgical treatment and late results. J Thorac Cardiovasc Surg 1980; 79: 523-31.

2) Moser KM, Daily PO, Peterson K, Dembitsky W, Vapnek JM, Shure, et al. Thromboendarterectomy for chronic, major-vessel thromboembolic pulmonary hypertension: immediate and long-term results in 42 patients. Ann Intern Med 1987; 107: 560-5.

3) Moser KM, Auger WR, Fedullo PF, Jamieson SW. Chronic thromboembolic pulmonary hypertension: clinical picture and surgical treatment. Eur Respir J 1992; 5: 334-42.

4) Thistlethwaite PA, Mo M, Madani MM, Deutsch R, Blanchard D, Kapelanski DP, et al. Operative classification of thromboembolic disease determines outcome after pulmonary endarterectomy. J Thorac Cardiovasc Surg 2002; 124: 1203-11.

5) Jamieson SW, Auger WR, Fedullo PF, Channick RN, Kriett JM, Tarazi RY, et al. Experience and results with 150 pulmonary thromboendarterectomy operations over a 29 -month period. J Thorac Cardiovasc Surg 1993; 106: 116-27.

6) Jamieson SW, Kapelanski DP, Sakakibara N, Manecke GR, Thistlethwaite PA, Kerr KM, et al. Pulmonary endarterectomy: experience and lessons learned in 1,500 cases. Ann Thorac Surg 2003; 76: 1457-64.

7) Ogino H, Ando M, Matsuda H, Minatoya K, Sasaki H, Nakanishi N, et al. Japanese single-center experience of surgery for chronic thromboembolic pulmonary hypertension. Ann Thorac Surg 2006; 82: 630-6.

8) Hartz RS, Byrne JG, Levitsky S, Park J, Rich S. Predictors of mortality in pulmonary thromboendarterectomy. Ann Thorac Surg 1996; 62: 1255-60.

9) Reesink HJ, van der Plas MN, Verhey NE, van Steenwijk RP, Kloek JJ, Bresser P. Six-minute walk distance as parameter of functional outcome after pulmonary endarterectomy for chronic thromboembolic pulmonary hypertension. J Thorac Cardiovasc Surg 2007; 133: $510-6$.

10) Sato M, Ando M, Muto A, Kondo $Y$, Hoshino R, Nishibe T, et al. Two cases of chronic pulmonary thromboembolism saved by postoperative use of a percutaneous cardiopulmonary support device. Ann Thorac Surg 2006; 82: 314-6. 